\title{
PCR Detection of the Three Neofabraea Pathogenic Species Responsible for Apple Bull's Eye Rot
}

\author{
Dongmei Cao ${ }^{1}$, Xin $\mathrm{Li}^{1}$, Jijuan $\mathrm{Cao}^{{ }^{*}}$, Weifang Wang ${ }^{2}$ \\ ${ }^{1}$ Liaoning Entry-Exit Inspection and Quarantine Bureau, Dalian, China \\ ${ }^{2}$ Guangdong Entry-Exit Inspection and Quarantine Bureau, Guangzhou, China \\ Email: *jj0909@163.com
}

Received January 4, 2013; revised February 5, 2013; accepted March 6, 2013

\begin{abstract}
Apple bull's eye rot is caused by pathogenic Neofabraea species including $N$. malicorticis, $N$. perennans and $N$. alba. Fruits carrying this fungal quarantine disease are prohibited from entering China. The host plants for the pathogens include several Rosaceae fruits including apple and pear. Disease symptoms and pathogen morphology are often insufficient to determine the identity of the pathogen, particularly at the species level. In the current study, we analyzed the inter-species sequence variations in the $\beta$-tublin gene, and designed specific primers to allow PCR amplification of 554 bp fragments from pathogenic Neofabraea species. The PCR products were recovered and sequenced, and Blast search was conducted using the DNA sequences in the Genbank database. The results indicated precise PCR amplification of the target sequences from the host pathogen, which allowed unambiguous identification of the species.
\end{abstract}

Keywords: Apple Bull’S Eye Rot; Neofabraea Spp; PCR; Detection

\section{Introduction}

Apple anthracnose (Bull's Eye Rot) has been a longstanding problem in the European and American apple industry for over a century [1], and contaminated fruits have been prohibited to enter China to prevent the fungal quarantine disease. In recently year, it has occurred regularly overseas and caused significant economic losses. Due to the heightened risk, China has classified it as Category A1 quarantine pest disease. Apple bull's eye rot is caused by species in the Neofabraea spp, previously classified into Pezicula before 1999 [2]. The pathogens causing apple bull's eye rot are primarily three Neofabraea species, namely $N$. malicorticis, $N$. perennans and $N$. alba [3,4]. Among them, N. malicorticis and N. perennans are regarded as the same species in Europe, different from the US.

These pathogens cause similar symptoms [5-8]. Onsite inspection and quarantine is conducted primarily through initial morphological assessment. In the early stage, the fruit skin shows only small spots. After several months of storage until the marketing stage, the small spots gradually enlarge to become round-shaped rot lesion of $1-2.5 \mathrm{~cm}$ in size or even greater. The lesions are typically flat or slightly sunken, light to dark brown in color. The central lightly colored area, light brown to

\footnotetext{
"Corresponding author.
}

yellow brown, resembles bull's eye, and the rotten tissue has a rigid texture. Based on the symptom characteristics and pathogen morphology, the disease can be tentatively concluded as apple bull's eye rot. However, limitation in the inspection and quarantine experience often diminishes the chance of conclusive assessment, especially when determining the specific species. In these cases, molecular biological methods are required to achieve rapid and accurate detection.

In the current study, we designed specific PCR primers based on the $\beta$-tublin gene sequences in order to identify the causative Neofabraea species. Specifically, the PCR products were sequenced, and the sequence was subjected to blast analysis in the Genbank database. The sequence comparison was found to allow accurate identification of the particular pathogen. In 2009, we successfully applied this method and identified the pathogen isolated from US-imported apple as $N$. perennans.

\section{Materials and Methods}

\subsection{Bacteria Strains}

This study used bacterial strains obtained from American Type Culture Collection (ATCC), Chinese Academy of Inspection and Quarantine (CAIQ), as well as isolates collected by Liaoning Entry-Exit Inspection and Quarantine Bureau (LNCIQ) from external sources (Table 1). 
Table 1. List of culture used.

\begin{tabular}{|c|c|c|c|}
\hline No. & Culture name & Reference & Source \\
\hline 1 & Neofabraea perennans & ATCC 26206 & ATCC \\
\hline 2 & N. perennans & ATCC 13904 & ATCC \\
\hline 3 & N. perennans & LN Np1 & LNCIQ \\
\hline 4 & N. perennans & LN Np2 & LNCIQ \\
\hline 5 & N. perennans & LN Np3 & LNCIQ \\
\hline 6 & N. morticisalic & ATCC 13903 & ATCC \\
\hline 7 & N. alba & ATCC 38338 & ATCC \\
\hline 8 & N. alba & ATCC 16504 & ATCC \\
\hline 9 & Leucostoma cincta & ATCC 64877 & ATCC \\
\hline 10 & Sphaeropsis pyriputrescens & MYA-2947 & ATCC \\
\hline 11 & Diaporthe perniciosa & ATCC 38578 & ATCC \\
\hline 12 & Leucostoma persoonii & ATCC 62911 & ATCC \\
\hline 13 & Phialophora malorum & ATCC 26778 & ATCC \\
\hline 14 & Venturia inaequalis & ATCC 11096 & ATCC \\
\hline 15 & Leptosphaeria maculans & L.m-21 & LNCIQ \\
\hline 16 & Fusarium solani & LD-3 & LNCIQ \\
\hline 17 & $\begin{array}{l}\text { Fusarium virguliforme } \\
\text { O'Donnell et }\end{array}$ & FV-171 & CAIQ \\
\hline 18 & $\begin{array}{l}\text { Monilinia } \\
\text { fructicola (Winter) honey }\end{array}$ & PB-1 & CAIQ \\
\hline 19 & Tilletia controversa Kühn & TCK-27 & CAIQ \\
\hline 20 & $\begin{array}{l}\text { Greeneria uvicola (Berk.er } \\
\text { M.A. Curtis) Punithalingam }\end{array}$ & GV-190 & CAIQ \\
\hline 21 & $\begin{array}{c}\text { Phoma medicaginis var. } \\
\text { medicaginis Malbr. \& } \\
\text { Roum }\end{array}$ & AV-13 & CAIQ \\
\hline
\end{tabular}

\subsection{Pathogen Isolation and Morphological Characterization}

Rotten tissues from affected apples devoid of conidia formation were collected and subjected to routine tissue separation methods. The samples were inoculated into potato dextrose agar (PDA) medium and incubated at $20^{\circ} \mathrm{C}$. Conidia were collected 3 days later for microscopy. If clearly visible at the lesion surface, conidia were directly used to prepare slides for light microscopy, and images were acquired to record the morphological features of the pathogen and to measure the size of the coindia.

\subsection{Design and Synthesis of PCR Detection Primer}

We used the National Center for Biotechnology Information (NCBI) database and conducted a comprehensive comparison of the sequences of $N$. malicorticis, $N$. perennans and $N$. alba. It was found that the highly con- served $\beta$-tublin gene shows species-specific sequence variations. Therefore, primers were designed to amplify a 554 bp fragment corresponding to part of the $\beta$-tublin harboring species-specific markers. The forward and reverse primers are as follows: F 5'-CTT TCT CCG TTG TCC CAT CC-3' and R 5'-GAA CAT TGC GCA TCT GGT CC-3', respectively. The primers were synthesized by Takara Bioengineering Co. (Dalian, China).

\subsection{DNA Extraction and PCR Amplification and Detection}

Promega SP fungal DNA kit was used to extract fungal DNA according to the manufacturer's instruction.

PCR reactions (30 $\mu \mathrm{L})$ contained the following components: $10 \times$ PCR buffer, $3 \mu \mathrm{L} ; 10 \mu \mathrm{mol} / \mathrm{L}$ primers, 1 $\mu \mathrm{L}$ each; $2.5 \mathrm{mmol} / \mathrm{L}$ dNTP, $4 \mu \mathrm{L}$; Taq DNA polymerase (TaKaRa, DRR030A; $5 \mathrm{U} / \mu \mathrm{L}$ ), $0.3 \mu \mathrm{L}$; template DNA (50 \pm 10 ng DNA), and $\mathrm{dH}_{2} \mathrm{O}$.

PCR reaction conditions were as follows: $94^{\circ} \mathrm{C} 2 \mathrm{~min}$; $98^{\circ} \mathrm{C} 10 \mathrm{sec}, 57^{\circ} \mathrm{C} 30 \mathrm{sec}, 72^{\circ} \mathrm{C} 30 \mathrm{sec}$, for 30 cycles; $72^{\circ} \mathrm{C} 5 \mathrm{~min} ; 4^{\circ} \mathrm{C}$ for storage.

The electrophoresis buffer $(1 \times \mathrm{TAE})$ was used to prepare a $1.2 \%$ agarose gel. The samples were prepared by mixing 10 - $15 \mu \mathrm{L}$ PCR amplification product with $2 \mu \mathrm{L}$ loading buffer, and loaded onto the gel with 100 bp Ladder DNA Marker. Electrophoresis was carried out at 110 $\mathrm{V}$ constant voltage for $20 \mathrm{~min}$. The gel was subjected to Goldview fluorescence staining and gel images were acquired.

\subsection{Sequence Analysis and Blast Comparison}

PCR products were recovered with PCR Fragment Purification Kit (TaKaRa, DV807A), sequenced by Takara (Dalian, China). The sequences were subjected to Blast search in the Genbank database and the identified homologous sequences were ranked according to sequence homology.

\section{Results}

\subsection{Specific PCR Amplification}

We investigated the specificity of PCR amplification using the reference bacterial strains shown in Table 1. As shown in Figure 1, following PCR amplification and electrophoresis, only $N$. malicorticis (ATCC 13903), $N$. perennans (ATCC 26206, ATCC 13904) and N. alba (ATCC 38338, ATCC 16504) produced the expected 554 bp positive amplification products which was absent in the other strains. Although faint bands were detected in a few strains, the sizes were clearly distinct from 554 bp. Together, these results indicated that the $\beta$-tublin PCR primers were highly specific for the pathogenic Neofabraea species responsible for apple bull's eye rot. 


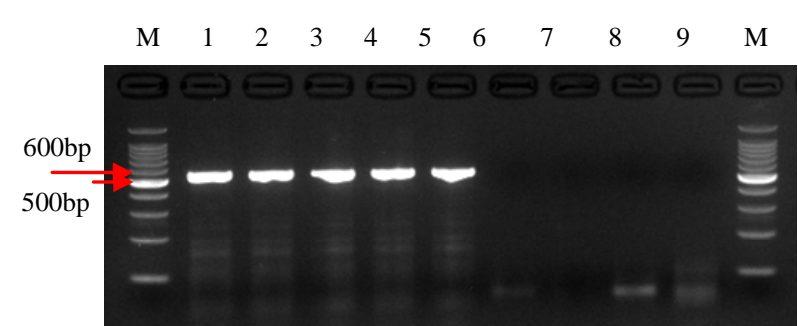

Figure 1. Electrophoresis of PCR amplification products of N. malicorticis, N. perennans and N. alba. M. 100 bp ladder DNA marker; 1) ATCC 26206; 2) ATCC 13904; 3) ATCC 13903; 4) АTCC 38338; 5) АTCC 16504; 6) АTCC 64877; 7) FV-171; 8) GV-190; 9) PB-1.

\subsection{Sequencing and Blast Search Analysis}

The positive PCR products described above were purified for sequencing, and the sequences were used as query for blast search of the Genbank database. The analysis revealed that the PCR product sequences derived from $N$. malicorticis (ATCC 13903), $N$. perennans (ATCC 26206, ATCC 13904) and N. alba (ATCC 38338, ATCC 16504) were identical to the Genbank $\beta$-tublin sequences from N.malicorticis (Genbank: AF281470, AF281469 etc.), $N$. perennans (Genbank: AF281476, AF281475, AF281474, AF281473 and AF281472) and N. alba (Genbank: AF281455, AF281454.1, AF281453 and AF281452). These results indicated that amplification of speciesspecific $\beta$-tublin gene fragments was able to distinguish the three pathogenic species, namely $N$. malicorticis, $N$. perennans and $N$. alba.

\subsection{Identification of Previously Collected Pathogen Samples}

In 2009, Liaoning and Guangdong Entry-Exit Inspection and Quarantine Bureau in China [9] independently identified contaminated samples exhibiting bull's eye rot. These samples were subjected to the above PCR analysis and the characteristic $\beta$-tublin gene fragments were observed, confirming the identity of the pathogen as one of the pathogenic Neofabraea species. The PCR products were sequenced, and blast search revealed that the sequences were identical to the $N$. perennans (Genbank: AF281476) $\beta$-tubulin DNA sequence (44 - 562 bp), indicating that the collected samples were caused by $N$. perennans.

The $N$. perennans $\beta$-tublin sequences obtained from these samples have been submitted to and accepted by Genbank (GU386354).

\section{Discussion}

In 1997, Altschul et al. completed the sequencing of $\mathrm{Ne}$ ofabraea genomes and submitted the sequences to Genbank [10]. Since the Internal Transcribed Spacers (ITS) regions among the Neofabraea species are highly similar, it is difficult to use these sequences to distinguish the species. A reliable method to identify the Neofabraea species should thus be based on selection of appropriate gene fragments with strong species specificity. To select the optimal gene fragment, we utilized the NCBI database, and conducted a comprehensive analysis of the inter-species sequence variation. Among several candidates, we selected the highly conserved $\beta$-tublin gene. Previously, $\beta$-tublin sequence variation was observed among Neofabraea species [6]. We determined that the conserved region can be used to design primers to amplify sequence containing species-specific sequences. Using both the forward and reverse $\beta$-tublin primers as the query sequences for Tax BLAST search, the results indicate $100 \%$ match with all homologous sequences from Neofabraea species.

In this report, we described for the first time a molecular biological method for detection of apple bull's eye rot pathogens, using $\beta$-tublin sequence markers to distinguish the three pathogenic Neofabraea species including $N$. malicorticis, $N$. perennans and $N$. alba. If the expected 554 bp PCR product is observed, the PCR product should be sequenced for blast search of the database to identify the species with the identical $\beta$-tublin sequence. Apple is a major fruit, and primarily produced north of the Yangtze River in China. The apple production industry plays an important role in local economy. Although bull's eye rot cases have not been reported in China, entry of the pathogens could cause severe loss in apply production. Therefore, the rapid and accurate molecular detection method described herein is important to minimize the risk of entry of the pathogens.

\section{Acknowledgements}

This study was supported by the Science and Technology Plan Project of Dalian City (No. 2009E11SF133).

\section{REFERENCES}

[1] L. Childs, "The Relation of Woolly Apple Aphis to Perennial Canker Infection with Other Notes on the Disease," The Valley Library, Corvallis, 1929.

[2] J. H. Cunnington, "Three Neofabraea Species on Pome Fruit in Australia,” Australia Plant Pathology, Vol. 33, 2004, pp. 453-454. doi:10.1071/AP04034

[3] N. Sharon, de Jong, C. A. Levesque, J. M. Gerard, Verkley, et al., "Phylogenetic Relationships among Neofabraea Species Causing Tree Cankers and Bull's-Eye Rot of Apple Based on DNA Sequencing of ITS Nuclear rDNA, Mitochondrial rDNA, and the b-Tubulin Gene," Mycological Research, Vol. 105, No. 6, 2001, pp. 658669. doi:10.1017/S0953756201003926

[4] G. J. M. Verkley, "A Monograph of the Genus Pezicula and Its Anamorphs,” Studies in Mycology, Vol. 44, 1999, 
pp. 1-180.

[5] G. Bompeix and D. Cholodowski-Faivre, "Thermotherapie et Produits Naturels, Unetechnologie Emergente,” L'arboriculture Frutiere, Vol. 542, No. 3, 2000, pp. 19-25.

[6] K. L. Edney, "Post-Harvest Pathology of Fruits and Vegetables,” In: C. Dennis, Ed., Top Fruit, Academic Press, New York, 1983, pp. 43-71.

[7] E. J. Guthrie, “The Occurrence of Pezicula alba sp. nov. and P. malicorticis, the Perfect States of Gloeosporium album and G. perennans, in England," Transactions of the British Mycological Society, Vol. 42, No. 4, 1959, pp. 502-506. doi:10.1016/S0007-1536(59)80052-8
[8] A. L. A. Snowdon, "Color Atlas of Post-Harvest Diseases and Disorders of Fruits and Vegetables," In: General Introduction and Fruits, CRC Press, Boca Raton, 1990, p. 320.

[9] W. F. Wang, J. Hu, Y. Y. Zhang, et al., "The First and Repetitious Interception in Guangdong Port of Bull's Eye Rot on Apple from US," Chinese Plant Quarantine, Vol. 24, No. 1, 2010, pp. 35-37.

[10] S. F. Altschul, T. L. Madden, A. A. Schaffer, et al., "Gapped BLAST and PSI-BLAST: A New Generation of Protein Database Search Programs,” Nucleic Acids Research, Vol. 25, No. 17, 1997, pp. 3389-3402. 